\title{
Logistics and E- Logistics Management: Benefits and Challenges
}

\author{
G. Kanagavalli, Ramseena Azeez
}

\begin{abstract}
Logistics Management is an effective system for the companies to deliver the products to the customers at the exact place where they demands at right time with right cost. Logistics management comprises the planning, implementation and control of the flow of raw materials and finished goods from the suppliers to the customers. This study is conducted to understand the conception of logistics and its significance. This study is to show the main functions of the logistics, aim, tactics and its various components. Nowadays most of the major companies are enforced to lessen their business expenditures because of the globalization and the companies are finding ways to reduce the costs without affecting the productivity. This made them to practice a new management tactics like Supply chain management and e-logistics. E-logistics provides the idea of logistics business into the modern world through the internet and completely changes the concept of simple logistics into e-logistics. E-logistics is the most modern technology in the field of logistics which brings the whole business world into a small online eworld. This novel set of communication with better computing and collective skills changes the new logistics into a customer oriented technology by data sharing, providing information and exact statistics with the supply chain customers. E-logistics helps in managing the new challenges in the supply chain field. The main components of the e-logistics are multi-channel operations, cross-border tasks, warehouse plan and inventory, planning, estimating and performance management. This study targets to understand the main benefits and the new tasks between logistics and e-logistics.
\end{abstract}

\section{I .INTRODUCTION}

Present day business world is exceptionally focused and a significant number of the organizations are attempting to be in the worldwide market and accomplish the upside of greatest generation and effective sourcing. The coordinations the executives were highly changed with the effect of web based business which brought new open doors just as difficulties to the co-ordinations. The organization's benefits are much relying upon the co-ordinations cost and transportation cost. The aggressive market and the different activities make greater difficulties on the co-ordinations office to convey the administration at the most punctual at a least cost. Co-ordinations assume a key job in the inventory network the board affirming the simpler progression of items and materials all through the store network of organization. These days, the co-ordinations is considered as the most dominant and significant factor in the advanced business advertise due to its physical appropriation and tasks nature.

Revised Manuscript Received on November 25, 2019.

* Correspondence Author

Dr. G. Kanagavalli is working as an Assistant Professor in the Department of Commerce, Alagappa University, Karaikudi

Ramseena Azeez is currently doing her Doctoral Research Scholar in the Department of Commerce, Alagappa University, Karaikudi
Co-ordinations are the matter of arranging and executing the tasks, obtainment, movement, and distribution of work force, materials and assets to accomplish the goals of a business venture. This is clarified as the stock administration in the development and very still. The utilization of on the web or electronic based innovations into the conventional co-ordinations capacity is called E-co-ordinations.

There are three fundamental components of the e-coordinations procedure to get a request from the customer Warehousing, conveyance and transportation and clients cooperations are those three principle segments and the client collaborations are done through a client care focus or call focus. This encourages the clients to raise the inquiries, issue the requests, Check its status and orchestrate the conveyance. Generally, different merchants are independently dealing with these three capacities. The profound information of these three capacities deals with the co-ordinations to be fruitful. Interfacing this three capacities one another and with the organization's present frameworks is exceptionally confounded.

\section{OBJECTIVES OF THE STUDY}

- To understand the term logistics and E-logistics

- To study the significance of logistics and $E$ logistics

- To understand the benefits and challenges of $\mathrm{E}$ logistics

\section{III .METHODOLOGY}

The study is based on a descriptive methodology involving secondary data collection. Tables, Graphs, Charts etc. were used for analyzing the data.

\section{LOGISTICS MANAGEMENT}

The Basic Principles of Logistics

The undertaking of co-ordinations which is the most extensively acknowledged definition today, and the accompanying to be the errand of co-ordinations: 'The activity of co-ordinations is to design, compose, control, and analyze the progression of materials and data inside and between/among frameworks, and to guarantee the equipment required for the execution of these assignments is accessible.' The reason for co-ordinations is that, pleasing pertinent needs:

-Right Product (administration/item constantly required at the time must be made displayed).

-Right Amount (lesser sums may causes stopping of generation, while greater sums may causes in working up stocks)

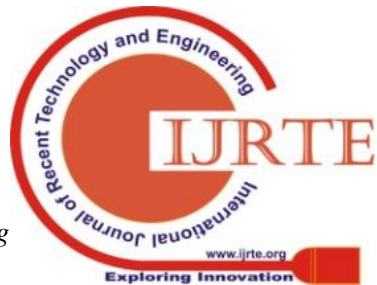




\section{Logistics and E- Logistics Management: Benefits and Challenges}

-Right Quality (administration/item quality ought to be guaranteed as per the customer prerequisites)

-Right Time (administration/item ought to be guarantee at the time required by the customer),

-Right Place (administration/item ought to be made present as per customer prerequisites)

-Right Cost (administration/item ought to be fix at the cost acknowledged by the customer) ought to be prepared for conveyance.

These six rights are called co-ordinations standards or the $6 \mathrm{R}$-guideline. The expansion of the correct way and with the correct gear took about the 7R standard, and later, dependent on how significant the data, the individuals or the vitality were separated from material further increases pursued the first 6R-rule.

Specialized writing as of now utilizes the augmentation of the 'right' guideline under the name of the 10R-rule, with exceptional respect to use in military co-ordinations. Strategic standards likewise uncover the calculated outlook as co-ordinations objectives not at decreasing the expense, however at advancing procedures, assessing a few angles.

Logistic objectives, the strategic elements of logistics

The strategic goals are surrounded based on calculated standards whereby the effectiveness of creation, and administration.

- Minimize conveyance time span

- Increase the utilization of limits

- Minimize stocks and overheads

- Increasing lucidity

- Generating and augment adaptability

- Making low ecological burden, applying reverberation amicable advancements

- Achieving high transportation abilities

- Improving customer delight and viability.

While planning the delight of these strategic targets the fulfillment of a solitary goal must not be seen as a confined issue, yet all calculated destinations ought to be for all intents and purposes considered simultaneously on a weighted premise.

Table 1 Logistic Aims.

\begin{tabular}{|l|l|}
\hline Minimize delivery target time & Shortening of throughput times \\
\hline Increase the use of capacities & Reduce Overheads, increase financial Strength \\
\hline Quality management & Discovering re-cycling methods \\
\hline Generating and maximize flexibility & Maximizing transparency \\
\hline Making low environmental emission & Echo friendly Technology \\
\hline Huge transportation capabilities & Enhancing International Cooperation \\
\hline Improving client gratification & Improving effectiveness. \\
\hline
\end{tabular}

What on-screen characters of the economy today anticipate from co-ordinations is the decreasing of coordinations related expenses, and accomplishing the appropriate standard of customer administration. It is significant in limit co-ordinations costs never to go for limit the expenses of individual components of the strategic framework or the calculated procedure, however seeing the idea of the frameworks approach, cost cutting must limit cost on the whole framework considering the relations among the components of the framework. Expanding the customer administration level is an instrumental goal in co-ordinations in light of the fact that lone those best adjusting to customer needs can win advertise rivalry, and that is unfeasible without increasing the expectations of strategic administrations. The accompanying figure speaks to the most significant key components required to accomplish strategic goals.

Table 2 Main Strategic Elements of Achieving Logistic Objectives

\begin{tabular}{|l|l|}
\hline Description of product & Enhancing cooperation \\
\hline Structure of Assets & Information Technology \\
\hline $\begin{array}{l}\text { The depth of production } \\
\text { (outsourcing, make or buy) }\end{array}$ & Communication System \\
\hline Managing & Recycling \\
\hline Customer Gratification & Logistic Environment \\
\hline
\end{tabular}

These most important strategic elements are as follows: The spreading of co-ordinations in every day financial

The structure of the calculated association

-The state of the item

-The equipment and the data framework

-The profundity of generation (re-appropriating, make or purchase)

- Capitalizing on upper hands by assessment with the best (benchmarking)

-Logistic controlling

-Recycling

- Customer Gratification

Factors affecting the development of logistics practice was made conceivable by dealing with the inventory creation utilization cycle taking the frameworks strategy, and the need of producing incorporated frameworks of material and data stream. Co-ordinations creates actuality impacted in a general sense by the accompanying components:

-An increment of the quantity of item types in showcase economies.

-The profundity of generation decline and the topic of 'make or purchase' is ending up progressively significant.

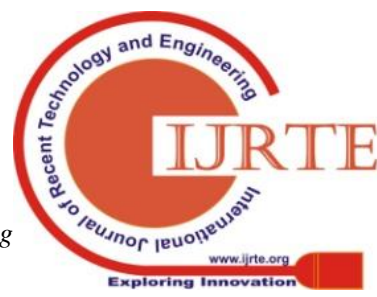


-Highly mechanized PC controlled gear, stockroom and storerooms, and robots are utilized for material handle.

-The standard of JIT (Just-in-Time) supply, generation and conveyance is making progress.

-Logistics appreciates advantage in business the executives, the ranking director of co-ordinations remain on the top managerial staff.

- Corporate co-ordinations is getting to be client arranged.

-Horizontal and vertical financial participation inside organizations is winding up progressively ordinary.

-Inter-organization collaboration is winding up increasingly vigorous.

-Corporate calculated administrations and exhibitions improve, uncommonly their quality.

-The theory of "lean creation" is ending up bit by bit well known.

-Process arranged reengineering is given more significance, in which business process reengineering is additionally given a job notwithstanding generation forms.

- Modern correspondence frameworks and electronic information and data trade are turned out to be across the board.

- Companies progressively focus on their center business, their principle profile, because of which they re-appropriate some strategic capacities.

-When structuring an organization's co-ordinations limit ecological effect (outflows) is turning into an essential thought, co-ordinations is assuming a significant job likewise in reverberation agreeable frameworks.

-The esteem chain is getting to be globalized.

- Logistic is giving more significance for IT.

The spreading of co-ordinations in financial life is ascribable to the way that it means another attitude that shows itself in the formation of a standard arrangement of material and information stream including acquirement, creation, and use. The most noteworthy accomplishment of co-ordinations in this way is it never again respects at the nuts and bolts of the strategic procedure exclusively, yet objectives at incorporating components and exercises.

\section{Significance of logistics management}

Organizations today are putting more prominent accentuation on co-ordinations the executives since it offers gigantic chances to fulfill clients, decrease expenses, and addition upper hand. A portion of the importance of coordinations is:

1. Focused edge: with developing challenge the advertisers need to find fresher and progressively innovative method for making an edge over his rivals. Successful co-ordinations the board is turning into a key to win and keep clients.

2. Successfully organized co-ordinations prompts positive business results: Logistics shows a fundamental part in store network the executives. It is utilized to plan and facilitate the development of items securely, auspicious and viably. Clients now not just from neighbors and nearby companions now the individuals from over the world. They are not thinking about separation; every client anticipates that their items should be come to rapidly and immaculately. So as to do this, brilliant organizations contract experienced experts can orchestrate the example of development of items in the most reasonable and viable manner.

3. Co-ordinations assist organizations with creating esteem: Providing an incentive to clients doesn't think to quality or amount it is alludes to accessibility too. The better co-ordinations makes items increasingly accessible to wide gathering of individuals, insightful business pioneers think of it as an exceptionally most significant apparatus in producing an incentive for clients. Co-ordinations makes and expands the worth organizations offer by improving product, and ensuring the accessibility of items.

4. Co-ordinations help in lessening costs and improves productivity: Global advertising developing progressively well known, co-ordinations has turned into the back conceived of supply chains. Business pioneers have acknowledged they can limit their expenses by building up associations with different organizations which offer transportation and warehousing.

5. Co-ordinations aides conveying the item at the perfect time and ideal spot: By choosing an accomplished group of experts, business people can guarantee quick and safe dispatching, warehousing and supply of their items to clients. They can consolidate these administrations such that increases the value of their offers, and assurance their items get to the ideal spot on schedule.

6. Consumer loyalty: Logistics framework will be concentrate to guarantee that the correct item, perfect spot, right hand and ideal time. Consequently, co-ordinations whenever oversaw appropriately, lead to elevated level of satisfaction among clients.

\section{Logistics activities or functions of logistics}

1) Order handling: The initial phase in Logistics is structure preparing, which will be crafted by the business division in an association. The business division ought to guarantee that the installment and the conveyance terms have been satisfied and after that procedures the request from inside the organization. On a very basic level, the business group gets the request from the client and submits the request to the distribution center. On the off chance that the client satisfies the installment, the business group makes the section into the framework and illuminates to convey the items. This is a significant advance in co-ordinations exercises in light of the fact that any error in this progression (wrong sections of amount, conveyance address and so on) can trouble the entire co-ordinations process.

2) Materials taking care of: The development of products inside the distribution center is called material dealing with is. It contains the board of the materials so that the distribution center can process arranges productively and adequately. It is a basic one and a proceeding with movement in all distribution centers. The distribution center administrator should know where the material to be put away and it ought to be appropriately dispatched to the dispatch focus of the stockroom, on the off chance that he is no doing this appropriately he will be in a tough situation and his profitability and productivity will endure a top dog.

3) Warehousing: warehousing assumes a gigantic job and is one of the critical Logistics movement. The key point in warehousing is that the stockroom must neighbor the seller or the wholesalers' place and it must empower the simple conveyance of merchandise.

4) Inventory control: Inventory the executives is one of the most essential elements of co-ordinations particularly after the reception of different creation strategies, for example, Just in time producing, lean assembling or other assembling forms where the expense of stock administration is cut down.

5) Transportation:

Transportation incorporates the physical conveyance of 
merchandise from the organization to the wholesaler or vendor or provider and from the seller or broker to the end clients. By and large, organizations convey merchandise to the sellers as it were. The provider is then answerable for the conveyance of products to the end clients. Notwithstanding, transportation is an expense to the seller or provider and it lessens his benefit along these lines the organization needs to give more noteworthy benefits to the vendor to repay his expenses.

6) Packaging: Packaging the item is the commitment of the group of co-ordinations in light of the fact that, in the event that it isn't finished by them the harmed item will reach to the end client and this will make awful impression and objection against the organization and it will bring about gigantic expense to the organization. This is the fundamental explanation, particularly in fare showcases; a higher sum is spent for the bundling of the item. The bundling may cost just $1-2 \%$ of the estimation of the item to the organization, yet in the event that it isn't exact during transportation, it will impact in $100 \%$ expense because of the harm, spillage and loss of the item.

\section{Components of logistics system}

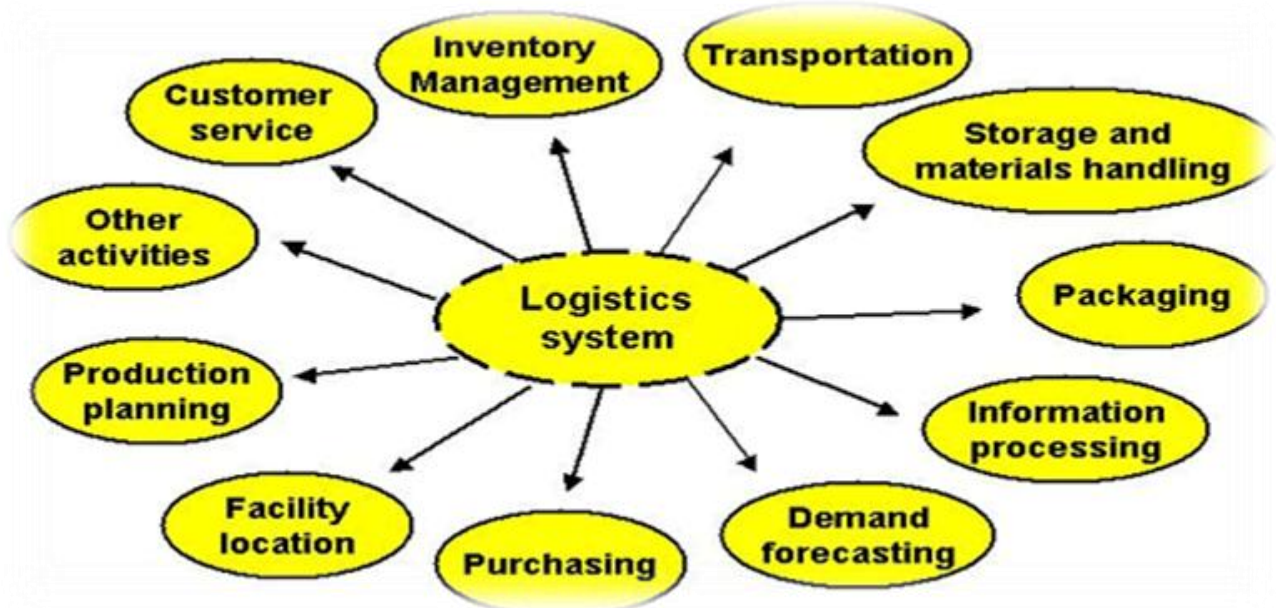

Figure 1: Components of Logistics System

\section{E-LOGISTICS MANAGEMENT}

E-Logistics offers access to all information just as a straight association with our vehicle and stockroom the board frameworks. E-Logistics conveys rushed and simple data pretty much all procedures along the production network. There are rich capacities existing for taking care of, control and straightforwardness. We can compute cargo charges, issue transport orders, track top to bottom procedure successions in the Warehouse, locate the careful items or outright help for our co-ordinations needs, or track our shipment progressively. It makes most extreme straightforwardness. E-Logistics is characterized as "the system of mechanizing co-ordinations forms and giving a joined, start to finish satisfaction and production network the board administrations to the players of co-ordinations forms."

E-calculated is the strategic procedure that deals with the entire thing identifies with the online commercial center. It is a moderately new idea. It is a lively arrangement of correspondence registering and working together innovations that convert key strategic procedures to the purchaser driven by sharing information, data and learning with production network pals. It helps in making due with recently rising co-ordinations challenges. The urgent components of co-ordinations are multi-channel activity, cross fringe usefulness, stockroom format and stock administration and arranging, execution the executives and so on. Accomplishment in co-ordinations is represented by the emphasis on choosing for the online shop. Other key factor that decides the accomplishment of e-strategic is appropriate affiliation, clear correspondence with clients for conveyance and returns and so on.

\section{Process involved in e-logistics}

1) Method of installment: There are two practical installment techniques. First at the phase of request that is called e-installment, charge card and so on second at the phase of conveyance called COD means money down. For electronic installment, an arrangement of confirmation of installment is required for delivery.

2) Check item accessibility: advise clients about accessibility regarding item before request is set. On the off chance that out of stock or the item will set aside effort to fabricate, advise clients about the deferral and interference.

3) Arrange shipments: it is the greatest action for E coordinations, since it require work, vitality, cash and so forth.

4) Insurance: This choice should be accessible for clients since item can be lost or harmed in the transportation procedure.

5) Replenishment: It must investigate all parts of physical stock at a site and reordering as required.

6) Contact with clients: With an indistinct procedure ( Indirect access activities), the customers should be educated more. Most common kind of interchanges is: request affirmation, installment achievement, shipping affirmation, following data and any issue simultaneously.

7) Returns: The progression of item from client to the sellers back is called invert co-ordinations. The plausible purposes behind clients to return or trade item are harmed item, item doesn't work, don't care for it , wrong item/type/shading and so forth.

The Benefits of E-Logistics

-Full straightforwardness over the whole co-ordinations procedure chain

- Time, cost, and asset reserve 
funds

-Higher edge

- Better efficiency

-Quick correlation

-Economy advantage

-User invitingness with the most elevated level of detail

-Individual versatility of the framework

- Real time choice help

-Shipper/beneficiary/satisfaction supplier associations

-Transportation enhancement

-Transportation documentation

-Wireless updates

-Track and follow

-Exception bases status alert

-Performance observing

- One co-ordinations stage for the executives of all things with repeating prerequisites

- Order preparing and sending happens through one framework

-Multi-provider skill and outsider provider fuse

-Connection to your ERP framework

-Management of your intralogistics

-Existing foundation will be exceptionally beneficial by methods for more noteworthy use

-Highly secure arrangement of provisions to the spots that have need of them

-Better productivity in distribution centers and at workstations.

\section{RESULT ANALYSIS}

\section{The Difference among Logistics and E-Logistics}

- Logistics includes arranging, execution of transport and treatment of products. E-co-ordinations is at last computerizing the calculated procedure.

- In request to fulfill and address the issues of the clients, co-ordinations plans, executes and controls the proficient, viable stream and capacity of merchandise, benefits, and related data from the purpose of-inception to the point-ofutilization. E-co-ordinations is characterized as the utilization of web grounded innovation to conventional coordinations forms.

- The volume of business on account of conventional coordinations is less on the grounds that like retail locations, a lot of products are sent to lesser areas. Where as on account of e-co-ordinations, it immediately sent the lesser measure of materials to numerous clients.

- The data were gathered in customary co-ordinations through fax, desk work and Management Information System (MIS), whereas on account of e-co-ordinations the data is gathered through Integrated IS, Internet, Radio Frequency Identification (RFID) and Electronic Data Interchange (EDI). The E-co-ordinations is extra solid and quick than contrasted with customary co-ordinations.

- In E-co-ordinations the clients have high expectation about help quality and conveyance of shipments where as on account of conventional co-ordinations speedy conveyance of items isn't at all conceivable and the client's desire were not addressed in light of the fact that now a days clients' needs faster conveyance of merchandise.

- There is less multifaceted nature in satisfying global exchange instance of conventional co-ordinations yet the intricacy is bigger to satisfying universal exchange e-coordinations. In e-co-ordinations it gives a possibility to put in direct requests with distributers and makers and furthermore helps in getting to more dealers all inclusive where as if there should be an occurrence of conventional co-ordinations it is chiefly finished through fax and paper functions as it is costly and acquire long time in accepting answer from makers and distributers.

\section{Challenges of e logistics}

Security: clients need to have assurance and confidence the installment technique supplier. In some cases, we can be deceived. The honesty and notoriety of the web stores must be investigated before taking purchasing choice.

Scalability of framework: To help huge number of clients one after another, an organization should needs a wellcreated site. In the event that our web goal isn't adequate, it will antagonistically influence the business.

Integrity on information and framework: All the time clients need secure access and assurance of information. Except if the exchange can offer it, we should rejects web based business.

Products individuals: a large portion of the clients were select and center around items which they have to feel, attempt and so on

Customer administration and connection issue: Build steadfast association with clients is particularly fundamental. Without faithfulness from clients, we can't endure the business. Now daily the challenge in the field of E-co ordinations and production network the board were likewise expanded.

E-Commerce co-ordinations are those exercises which assurance the clients to get what they need at ideal time at ideal spot and at lower cost. Web based business coordinations face numerous difficulties in creating nations, as higher taxes, convoluted worldwide exchange rules, topographical hindrances and worldwide fear based oppression. The absence of information of complete expense in online dealer is the fundamental driver for the disappointment of numerous electronic trades in past decades.

In creating nations the difficulties of e-co-ordinations are absence of framework, financial and instructive hindrances, channel clashes, conveyance co-ordinations, security issues security, trust and protection, and worldwide fear based oppression and topographical boundaries. Absence of financial assets, web utilization and standard of training are the fundamental hindrances for e-co-ordinations and so on comprises in monetary and instructive obstructions. Just propelled clients in creating nations were utilized the vast majority of e-co-ordinations in light of absence of assets to utilize the web and shop on the web. Absence of framework incorporates creating nation's poor media transmission foundation and little access of PCs produce obstruction in eco-ordinations. Web access cost likewise bring about boundary to e-co-ordinations. Security, protection and trust is distinctive in various nations and there is no arrangement in numerous nations govt decides that e-co-ordinations ought to be legitimately official and trust commendable all things considered it make hindrances in E-co-ordinations. 


\section{CONCLUSION}

Utilization of innovation in the conventional strategies for business has offered establishment to E-Logistics. Because of E-Logistics, Consumer satisfaction rate has expanded. The essentialness of e-co-ordinations has becoming because of globalization. The value of e-co-ordinations can't be disregarded despite the fact that there are such a large number of difficulties. So as to utilize e-co-ordinations successfully and ingeniously, we ought not abuse it first ie, it must utilize it on a legitimate way and ought to perceive the quality and shortcoming of e-co-ordinations well. To wrap things up in the coming future the significance of e-coordinations will be more noteworthy than that of the current condition and it will be utilized by numerous individuals sooner rather than later.

Straightforwardness and limpidity in the business has improved, need to break down and furthermore the capacity to investigate the business has improved in light of use of innovation. As indicated by Hesse 2002, Gunasekaran et.al 2003, E-co-ordinations is a web supported co-ordinations worth chain that offer humble co-ordinations administrations like agreement warehousing, open warehousing, appropriation the executives, target union and transport the executives. E-co-ordinations is a blend of four parts including one stop worth included administrations, data the board, robotization in warehousing system and a transportation arrange. so as to create consumer loyalty the one stop worth included administrations were makes a difference. Data the board is the place the data is traded by means of electronic media resembles WWW, EDI and Internet. Mechanization in warehousing activity will diminish human cooperation in refreshing solidification, stacking and emptying. A Transportation system develops adaptability and reducing the expense of transportation.

\section{REFERENCE}

1. J P Mahajan,Anupama Mahajan, Marketing Management, kalyani publication

2. Dr. P. Rajan Chinna and Aravindaraj. K (2019), "A Review on Recent Developments in Logistics and Supply Chain Management in India”, IOSR-JBM, Vol-21, Issue-10 (Series-III), pp: 06-08.

3. Aravindaraj. K and Dr. P. Rajan Chinna (2019), "Social Media Marketing and its Impact", National Conference on Implications of Internet Marketing, Feb - 2019.

4. Philip Kotler, Marketing Management,

5. Sunthakki, Marketing Management,Himalaya publication

6. S chand, Marketing Management, Himalaya Publication

7. www.forbes.com/specialsections/elogistics

8. https://www.basenton.com/NEWS/Company-News/thecharacteristics-of-logistics-management.html

9. https://www.business-standard.com/article/opinion/what-is-greenlogistics-and-why-is-it-important-for-india-115080600426 1.html

10. www.emeraldinsight.com/journal.html

\section{AUTHOR PROFILE}

Dr. G. Kanagavalli is working as an Assistant Professor in the Department of Commerce, Alagappa University, Karaikudi. She has published many articles in International and National conferences.

Ramseena Azeez is currently doing her Doctoral Research Scholar in the Department of Commerce, Alagappa University, Karaikudi. She also published many articles in International and National conferences. 